\title{
Post-Earthquake Damage Evaluation of Reinforced Concrete Buildings
}

\author{
Masaki Maeda ${ }^{1}$ and Dae Eon Kang ${ }^{2}$
}

Received 3 June 2009, accepted 29 September 2009

\begin{abstract}
The authors have developed a method to evaluate the residual seismic capacity of reinforced concrete structures damaged by earthquakes, which is employed in the Guideline for Post-Earthquake Damage Evaluation and Rehabilitation. Presented in this paper are outlines of the damage rating procedures based on the residual seismic capacity index $R$, defined as the ratio of residual seismic capacity to original capacity. The procedure was applied to low-rise reinforced concrete buildings damaged in recent earthquakes in Japan including the 1995 Hyogo-Ken-Nambu (Kobe) Earthquake and its validity was discussed. Good agreement between the residual seismic capacity index $R$ and damage levels observed in damaged buildings was found. Moreover, nonlinear seismic response analyses of single-degree-of-freedom (SDF) systems were carried out. It was observed that the residual seismic capacity of a damaged RC building structure can be evaluated conservatively according to the $R$ index employed in the Guideline, and from a practical point of view, the $R$ index is an effective way to identify the safety of damaged structures against aftershocks.
\end{abstract}

\section{Introduction}

To restore an earthquake damaged community as quickly as possible, a well-prepared reconstruction plan is essential. When an earthquake strikes a community and destructive damage to buildings occurs, quick damage inspections are needed to identify which buildings are safe and which are not in the case of aftershocks. However, since such quick inspections are performed within a short period of time, the results are inevitably coarse. In the next stage following the quick inspections, damage evaluation should be more precisely and quantitatively performed. For this purpose, a technical guideline that may help engineers find appropriate actions required in a damaged building is needed. In Japan, the Guideline for Post-Earthquake Damage Evaluation and Rehabilitation (JBDPA 2001a) (subsequently referred to as Damage Evaluation Guideline) originally developed in 1991 was revised in 2001 based on lessons from damaging earthquakes such as the 1995 Hyogo-Ken-Nambu (Kobe) Earthquake.

The authors have developed a method to evaluate the residual seismic capacity of reinforced concrete structures damaged by earthquakes (Maeda and Bunno 2001, Maeda et al. 2004), which is employed in the Damage Evaluation Guideline revised in 2001. An outline of the damage rating procedures based on the residual seismic capacity index $R$ is presented in this paper. The procedure was applied to reinforced concrete buildings damaged in the Kobe earthquake and their validity was discussed. Moreover, nonlinear seismic response analyses of sin-

${ }^{1}$ Associate Professor, Department of Architecture and Building Science, Tohoku University, Sendai, Japan. E-mail:maeda@archi.tohoku.ac.jp

${ }^{2}$ Research Associate, Kwangwoon University, Seoul, Korea. gle-degree-of-freedom (SDF) systems were carried out to investigate the accuracy of the residual seismic capacity index $R$.

\section{Post-earthquake damage evaluation}

(1) Residual seismic capacity ratio, $R$ index

The structural damage state of RC buildings is identified using the residual seismic capacity ratio, $R$ index, in the Damage Evaluation Guideline (JDBPA 2001a). The $R$ index is defined as the ratio of post-earthquake seismic capacity to original capacity and is given by Eq. (1).

$$
R=\frac{{ }_{D} I S}{I S} \times 100(\%)
$$

where $I s$ and ${ }_{D} I s$ represent the seismic performance index of the structure before and after earthquake damage, respectively. The $I s$ index, which is defined in the Japanese Standard for Seismic Evaluation of Existing RC Buildings (JBDPA 2001b) (subsequently referred to as Seismic Evaluation Standard), is widely applied to seismic evaluation of existing RC building structures in Japan. The $I s$ index is evaluated based on the ultimate lateral strength index $(C$ index) and ductility index $(F$ index) of each lateral-load resisting member. The basic concept of the $I s$ index is described in the Appendix.

\section{(2) Estimation of post-earthquake seismic ca- pacity}

Similarly, the post-earthquake seismic capacity ${ }_{D} I s$ index is evaluated based on the $C$ and $F$ indices. However, both indices are calculated using seismic capacity reduction factors ( $\eta$-factors), which are described in detail later, to consider the deterioration of lateral strength and ductility corresponding to the damage state of each lateral-load resisting member.

In the Damage Evaluation Guideline (JDBPA 2001a), 
the state of damage of each structural member is first classified into one of the five classes listed in Table 1. The relationship between each damage class given in Table 1 and the lateral strength- displacement curve is approximated as shown in Fig. 1.

In Fig. 1(a), a ductile member deforms up to a maximum lateral strength level after yielding. Furthermore, after reaching the maximum strength, the reduction of strength is relatively small. If the maximum deformation during an earthquake does not reach deformation at yielding point, extensive damage would not occur. This state corresponds to damage class I, between the cracking and yield points. If the maximum deformation does not exceed the maximum strength, damage to cover concrete is limited and most of the lateral and vertical strengths remains in the flexural member. This state corresponds to damage class II and damage class III. If the maximum earthquake response exceed the maximum lateral strength point, deterioration in lateral strength with spalling of cover concrete would be observed. The vertical strength may remain if the buckling and/or fracture of reinforcing bars and crush of core concrete, etc., do not occur. This state corresponds to damage class IV. If buckling and/or fracture of reinforcing bars and crush of core concrete occur, both the lateral and vertical load carrying capacities will be lost (damage class V).

The degree of damage in a brittle member, as shown in Fig. 1(b), is similar to that of a ductile member up to the maximum strength, although diagonal or X-shape cracks may also be visible (damage classes I, II and III). After the maximum strength is reached, a significant reduction in both lateral and vertical strength may occur (damage class IV). Finally, X-shape shear cracks widen and both lateral and vertical load carrying capacity will be lost suddenly (damage class V).

The seismic capacity reduction factors, i.e., $\eta$ factors for structural member corresponding to the damage classes, are listed in Table 2 . The $\eta$ factors are determined from the residual crack width and the overall damage state of RC columns observed in the author's laboratory experiments (Bunno and Maeda 1999) and analytical studies (Maeda et al. 2001, Maeda et al. 2004). In the Seismic Evaluation Standard, the most fundamental component for the $I s$ index is the $E_{0}$ index, which is calculated from the product of the strength index $(C$ index) and the ductility index ( $F$ index) (see Appendix).

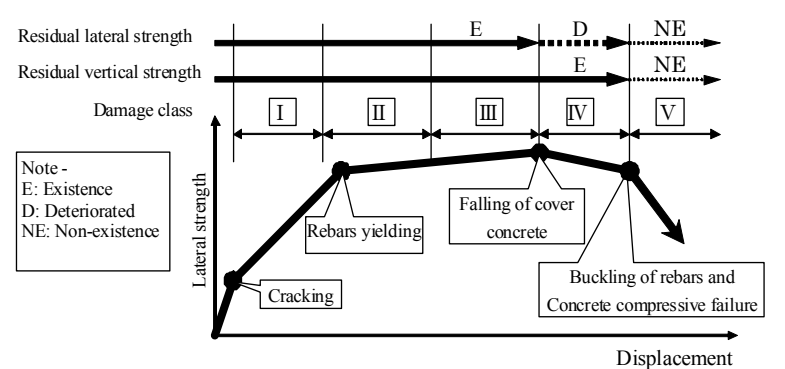

(a) Ductile member

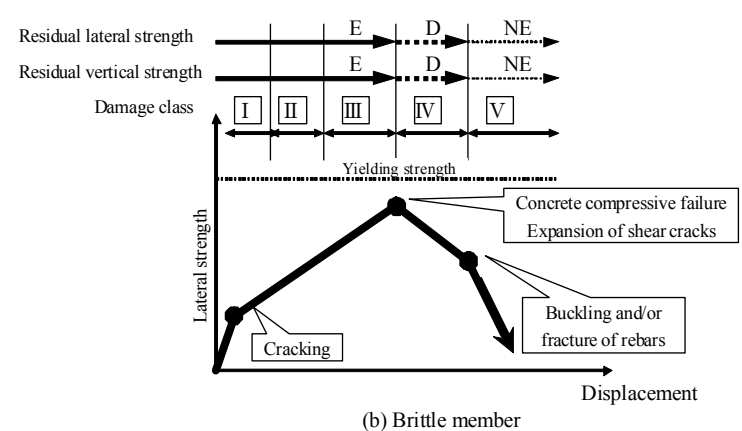

Fig. 1 Approximated lateral force-displacement relationships and damage classes (JBDPA 2001a).

Table 2 Seismic capacity reduction factor $\eta$.

\begin{tabular}{|c|c|c|c|}
\hline $\begin{array}{c}\text { Damage } \\
\text { class }\end{array}$ & $\begin{array}{c}\text { Ductile } \\
\text { column }\end{array}$ & $\begin{array}{c}\text { Brittle } \\
\text { column }\end{array}$ & $\begin{array}{c}\text { Shear } \\
\text { wall }\end{array}$ \\
\hline I & 0.95 & 0.95 \\
\hline II & 0.75 & 0.6 \\
\hline III & 0.5 & 0.3 \\
\hline IV & 0.1 & 0 \\
\hline V & 0 & 0 \\
\hline
\end{tabular}

Accordingly, the $E_{0}$ index corresponds to the energy dissipation capacity in a structural member. Figure 2 shows a conceptual diagram illustrating the lateral strength-displacement curve and a definition of the $\eta$ factors. When the maximum response reaches point $\mathrm{A}$ (Fig. 2) during an earthquake and residual displacement (point B) occurs, the area of $E_{d}$ and $E_{r}$ is assumed to be the dissipated energy during the earthquake and the residual energy dissipation capacity after the earthquake, respectively. The $\eta$ factor is defined as the ratio of residual energy dissipation capacity, $E_{r}$, to original energy

Table 1 Definition of damage classes of structural members (JBDPA 2001a).

\begin{tabular}{|c|l|}
\hline Damage Class & \multicolumn{1}{|c|}{ Description of damage } \\
\hline I & Visible narrow cracks on concrete surfaces. Crack widths are less than $0.2 \mathrm{~mm}$. \\
\hline II & Visible cracks on concrete surfaces. Cracks widths range from about 0.2 to $1 \mathrm{~mm}$. \\
\hline III & $\begin{array}{l}\text { Noticeable wide cracks. Cracks widths range from about 1 to 2 mm. Localized } \\
\text { crushing of concrete cover. }\end{array}$ \\
\hline IV & $\begin{array}{l}\text { Crack widths are greater than 2 mm. Crushing of concrete with exposed reinforcing } \\
\text { bars. Spalling of cover concrete. }\end{array}$ \\
\hline V & $\begin{array}{l}\text { Buckling of reinforcing bars. Crushing of core concrete. Visible vertical deformation } \\
\text { in columns and/or shear walls. Side-sway, subsidence of upper floors, and/or frac- } \\
\text { ture of reinforcing bars are observed in some cases. }\end{array}$ \\
\hline
\end{tabular}




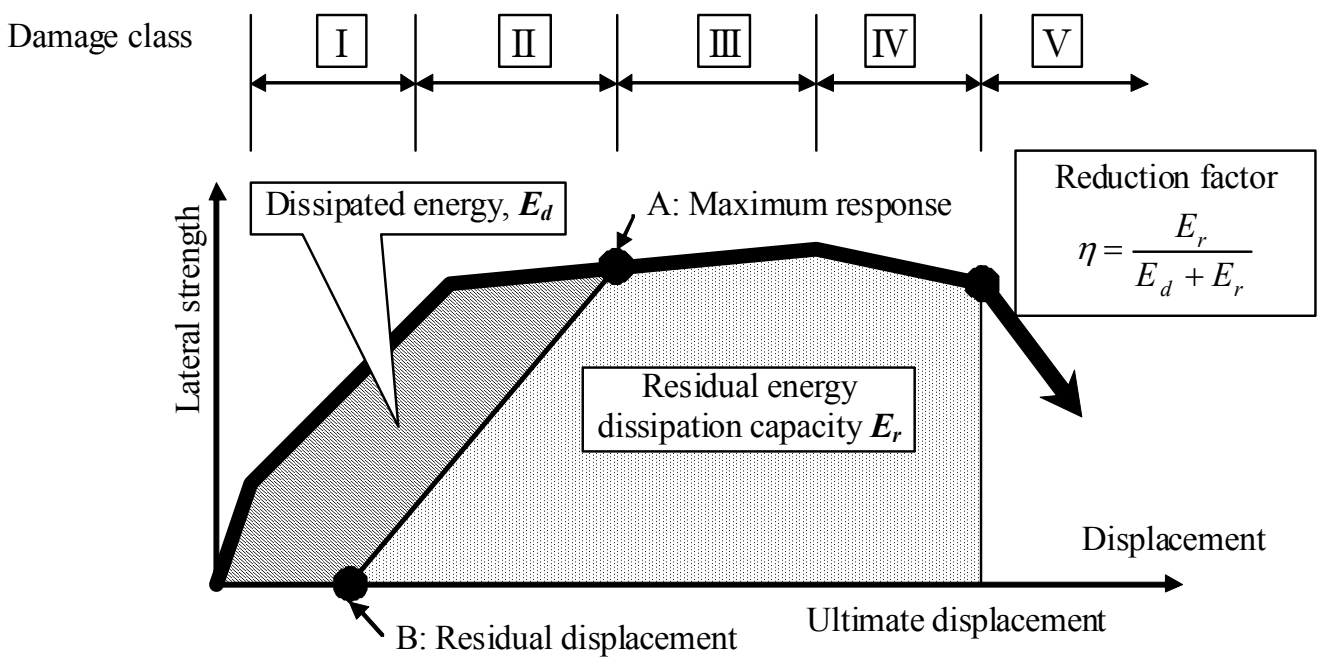

Fig. 2 Conceptual diagram of seismic capacity reduction factor $\eta$.

dissipation capacity, $E_{t}\left(=E_{d}+E_{r}\right)$, and can be calculated by Eq. (2).

$$
\eta=\frac{E_{r}}{E_{t}}
$$

where, $E_{d}$ : dissipated energy, $E_{r}$ : residual energy dissipation capacity and $E_{t}$ : original energy dissipation capacity $\left(E_{t}=E_{d}+E_{r}\right)$.

The values for the $\eta$ factors for ductile and brittle columns listed in Table 2 were determined by the Maeda's studies as mentioned above and are employed in the Damage Evaluation Guideline. The Guideline recommends the same values with brittle columns to shear walls. The post-earthquake seismic capacity, ${ }_{D} I s$ index, of the overall building after earthquake damage can be calculated based on the $E_{0}$ index reduced by the $\eta$ factor corresponding to the observed damage class of each structural member.

\section{(3) Estimation of lateral strength and ductility}

One of the main purposes of damage level classification is to grasp the residual seismic capacity as soon as possible just after the earthquake, in order to assess the safety of the damaged building with regard to aftershocks and to judge the necessity for repair. For this purpose, a detailed and complicated procedure, i.e., calculation of lateral strength $(C$ index) and ductility ( $F$ index) of structural members based on material and sectional properties, reinforcing details, etc., is inconvenient. Therefore, a simplified method to approximate the residual seismic capacity ratio, the $R$ index, was developed using the following assumptions.

(1) The lateral load resisting members are grouped into five categories as shown in Table 3: flexural columns (F), shear columns (S), shear walls without boundary columns (W), shear walls with one boundary column $(\mathrm{CW})$, and shear walls with two boundary columns (CWC).

(2) The cross section areas for the five categories are assumed as shown in Table 3 based on statistic studies of low-rise RC buildings such as school buildings in Japan. The average shear stresses for the five categories are approximated by the values shown in Table 2, which are generally used in the first level evaluation in the Seismic Evaluation Standard (JDBPA2001b). The relative values of the strength index, $C$, for the five categories can be obtained as 1:1:1:2:6 from the assumptions above.

(3) The ductility index $F$ of each vertical member is

Table 3 Categories of vertical members and relative lateral strengths $C$.

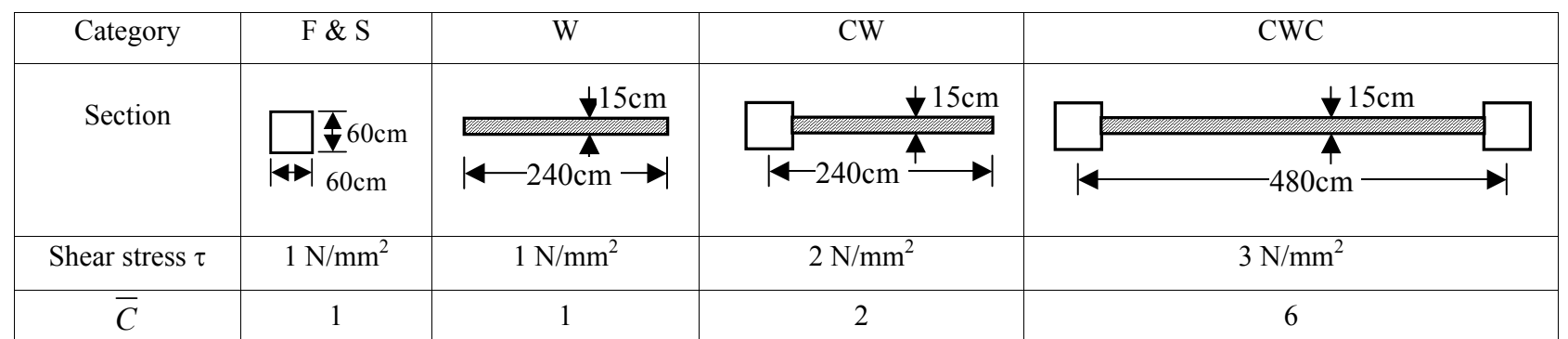

Note- F: flexural columns, S: shear columns, W: shear walls without boundary columns, CW: shear walls with one boundary column, CWC: shear walls with two boundary columns. 
assumed to be 1 .

(4) The $I s$ and ${ }_{D} I s$ indices are computed using these ratios of vertical members in the damaged story.

The approximated $R$ index is calculated by Eq. (3).

$$
R=\frac{\sum \eta \bar{C} F}{\sum \bar{C} F}
$$

\section{Application to buildings damaged due to recent earthquakes in Japan}

The proposed damage evaluation method was applied to reinforced concrete buildings damaged due to recent earthquakes such as the 1995 Hyogo-Ken-Nambu (Kobe) Earthquake. The target buildings included 10 moment frame structures and 2 wall-frame structures (Maeda et al. 2004).

In Fig. 3, the approximated residual seismic capacity ratio $R_{1}$ by Eq. (3) was compared with precise value $R_{2}$, which was evaluated from the $I s$ and ${ }_{D} I s$ indices computed based on material strength, sectional properties and reinforcing details according to the Seismic Evaluation Standard. Figure 3 shows a good agreement between $R_{1}$ and $R_{2}$ for both frame and wall-frame structures.

The approximated residual seismic capacity ratio $R$ of about 150 reinforced concrete school buildings damaged in the Kobe Earthquake, including the above-mentioned buildings, are shown in Fig. 4 together with the observed damage levels from field surveys. The horizontal lines in Fig. 4 are the boundaries between damage levels employed in the Damage Evaluation Guideline.

$$
\begin{array}{lc}
\text { [slight damage] } & R \geq 95 \% \\
\text { [minor damage] } & 80 \leq R<95 \% \\
\text { [moderate damage] } & 60 \leq R<80 \% \\
\text { [severe damage] } & R<60 \% \\
\text { [collapse] } & R \approx 0
\end{array}
$$

The damage levels based on the $R$ index described above generally agree with the damage levels classified by investigators. The boundary line between slight and minor damage was set to $\mathrm{R}=95 \%$ to harmonize "slight damage" to the serviceability limit state in which repair is not required and buildings may be functional. Almost all severely damaged buildings and approximately $1 / 3$ of moderately damaged buildings were demolished and rebuilt after the earthquake according to a report of the Hyogo Prefectural Government (1998). If the boundary between moderate and severe damage was set to $\mathrm{R}=60 \%$, "moderate damage" may correspond to the repairability limit state.

\section{Calibration of $R$ index with seismic response of SDF systems}

\section{(1) Outline of analysis}

In the Damage Evaluation Guideline (JBDPA 2001a), the seismic capacity reduction factor $\eta$ was defined as the ratio of the residual energy dissipation capacity, $E_{r}$, to the

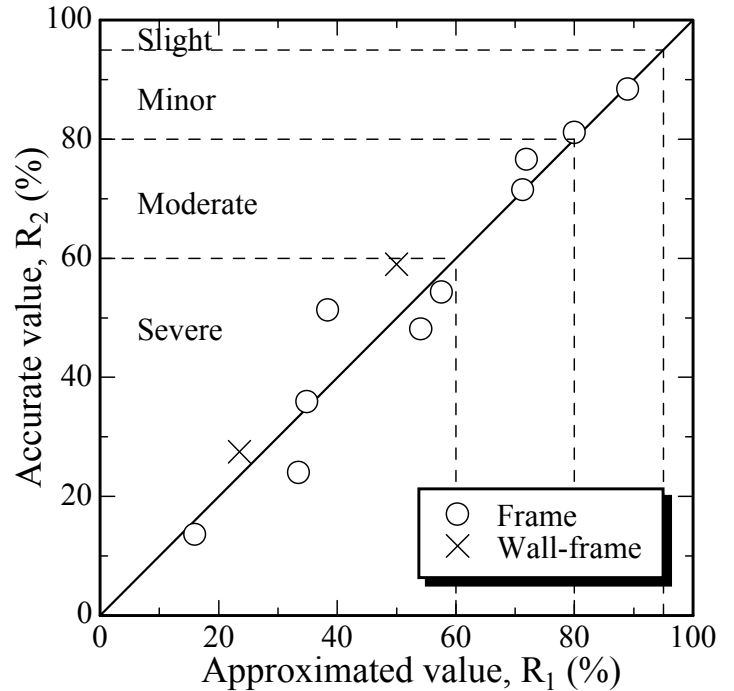

Fig. 3 Comparison of approximated and precise $R$ index.

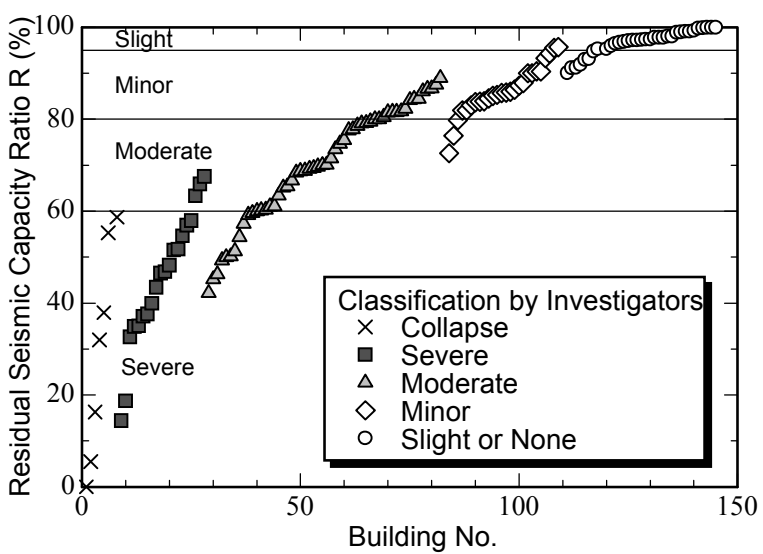

Fig. 4 Residual seismic capacity index $R$ and observed damage levels due to Kobe Earthquake.

original capacity, $E_{t}$, in a monotonic lateral strength-displacement (Fig. 2). Thus the effect of cyclic behavior during seismic excitation was not taken into account. Nonlinear seismic response analyses of single-degree-of-freedom (SDF) systems were carried out to examine the validity of the residual seismic capacity ratio $R$ in the Guideline. For this purpose, the residual seismic capacity ratio based on seismic response, $R_{d y n}$ index, was introduced. Figure 5 shows a conceptual diagram of the intensity of ground motion when a structure with various levels of damage collapses. A no-damage structure is generally expected to withstand earthquakes with higher intensity, while damaged structure may collapse in earthquakes of lower intensity (Fig. 5). In this study, the maximum intensity of ground motion that a structure is able to withstand was regarded as the seismic capacity of the structure. The residual seismic capacity ratio based on seismic response, $R_{d y n}$, was defined by the ratio of the maximum intensity of ground motion after damage to that of no-damage. 


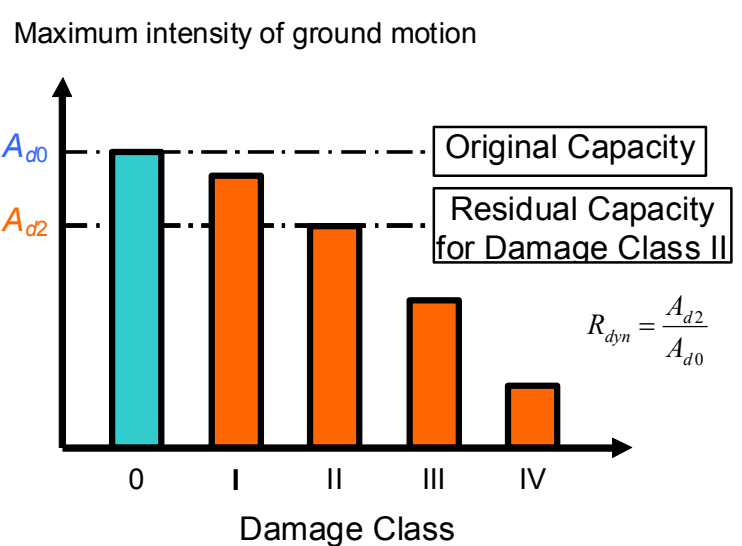

Fig. 5 Maximum intensity of ground motion with different damage states and concept of $R_{d y n}$ index.

$$
R_{d y n}=\frac{A_{d i}}{A_{d 0}}
$$

where, $A_{d 0}$ : maximum intensity of ground motion before an earthquake (damage class 0 ) and $A_{d i}$ : maximum intensity of ground motion after damage (damage class " $i$ ")

The maximum intensity of ground motion was evaluated from nonlinear seismic response analyses of SDF systems with various levels of damage. The details of the evaluation procedure are described later.

\section{(2) Hysteresis model}

The Takeda hysteresis model (Takeda et al. 1970) is one of the most popular models for representing RC components. In this study, two modifications to the Takeda model were performed to represent the pinching behavior after yielding and the deterioration in lateral strength in the range exceeding maximum strength (damage classes IV and V). The hysteresis rule is shown in Fig. 6. The model behaves in the same manner as the Takeda model on the primary curve. The primary curve is a tri-linear shape with a change in stiffness at the cracking point $\left(d_{c}\right.$, $\left.F_{c}\right)$ and yield point $\left(d_{y}, F_{y}\right)$, as shown in Fig. 6(a). When unloading occurs from a point on the primary curve, the unloading point is considered to be a new yield point. The model behaves in the same manner as a bi-linear model between the positive and negative yield points with a degraded unloading stiffness $K_{r}$. After yielding occurs, the pinching behavior in the inner loop between the positive and negative maximum responses is considered with modified stiffnesses $K_{s 1}$ and $K_{s 2}$ (Fig. 6(b)). Once the maximum response exceeds the maximum strength point $\left(d_{\max }, F_{\max }\right)$, the intersection (point $\mathrm{A}$ in Fig. 6(c)) of reloading curve $(A B)$ and strength declination line $(\mathrm{CD})$ is assumed to be a new yield point in order to consider deterioration in lateral strength in the range of damage of class IV and V.

In the analytical study, yield load $F_{y}$ was chosen to be the base shear coefficient of 0.3 . Cracking resistance $F_{c}$

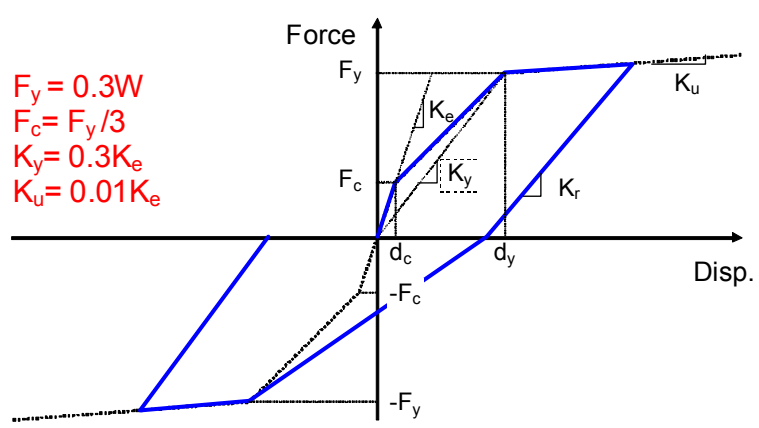

(a) Primary loop

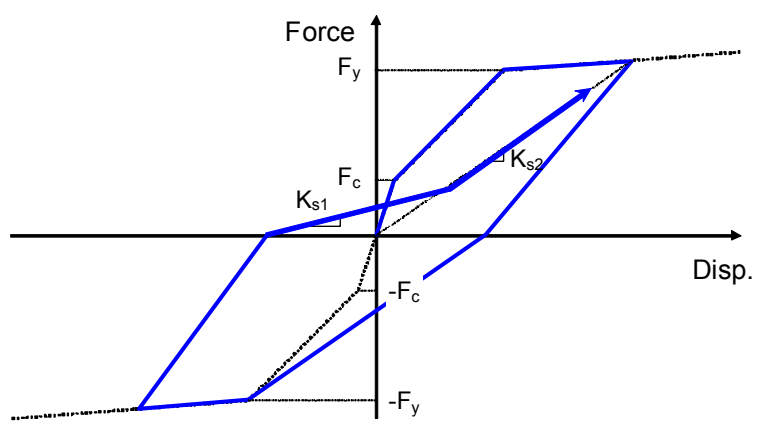

(b) Inner loop after yielding

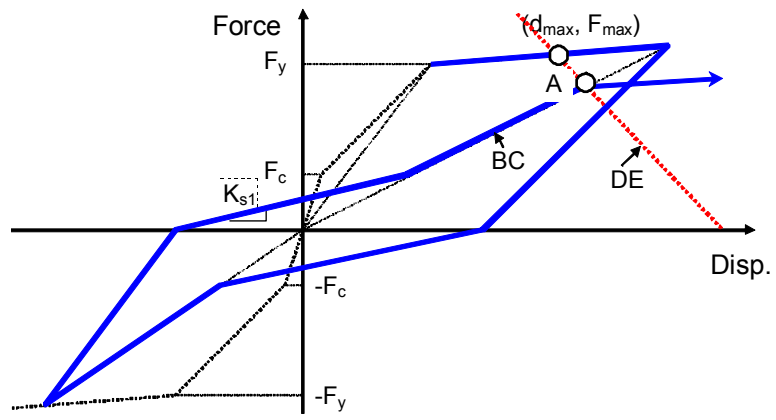

(c) Deterioration after maximum lateral strength

Fig. 6 Hysteretic model.

was one-third the yielding resistance $F_{y}$. Initial stiffness $K_{e}$ was designed so that the elastic vibration periods $T$ were $0.1,0.2,0.3,0.4,0.5$ and $0.6 \mathrm{~s}$. The secant stiffness at the yielding point, $K_{y}$, and the post-yielding stiffness, $K_{u}$, were 30 and 1 percent of the initial stiffness, respectively.

\section{(3) Analytical parameters}

Three primary curves with different deformation capacities, as shown in Fig. 7, were employed in the analyses. Ductility factor $\mu$ is defined as the ratio of the displacement response $(d)$ to the yield displacement $\left(d_{y}\right)$, i.e. $d / d_{y}$. The load-displacement relationships of the RC column experiment (Jung and Maeda 2000) and the range of corresponding damage classes are also shown in the figure. If the ductility factor $\mu$ exceeds the maximum strength point $\left(\mu_{\max }\right)$, the damage class of the system reaches IV and the lateral strength begins to decline 
(a) Brittle Column $\mu_{\max }=1.5, \mu_{u}=2$

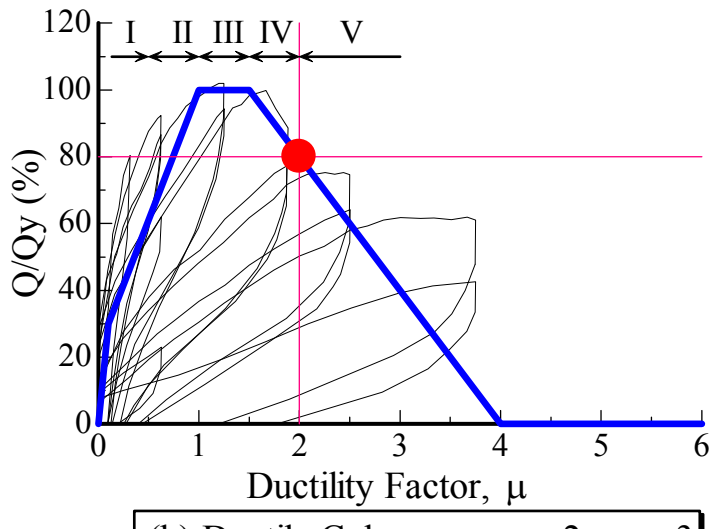

(b) Ductile Column $\mu_{\max }=2, \mu_{\mathrm{u}}=3$

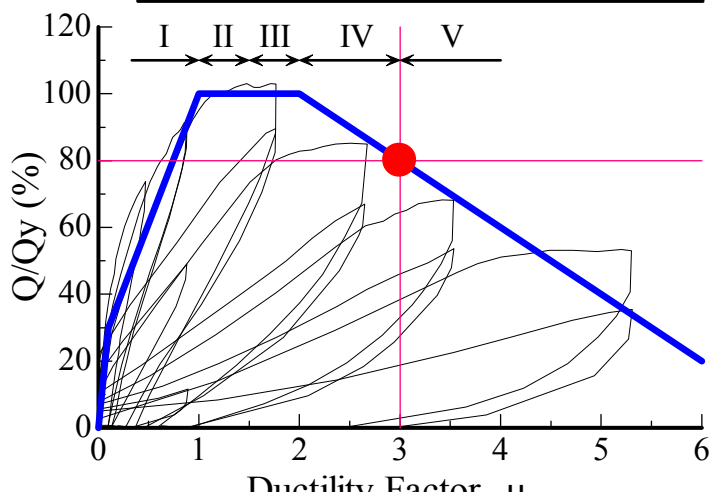

Ductility Factor, $\mu$

(c) Ductile Column $\mu_{\max }=3, \mu_{u}=5$

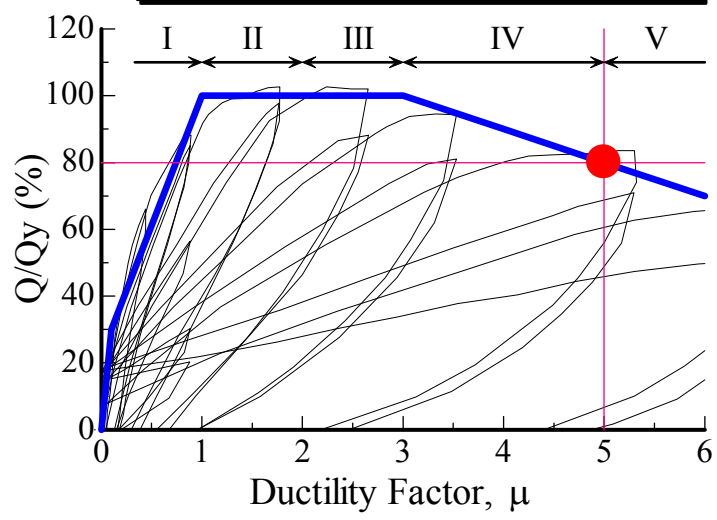

Fig. 7 Primary curve for analysis and column experimental results.

linearly. The displacement at which lateral strength declines to 80 percent of the maximum is assumed to be ultimate state $\left(\mu_{u}\right)$.

Figure 7(a) represents a brittle structure in which lateral strength reached the maximum at $\mu_{\max }=1.5$ and ultimate displacement is 2 times the yield displacement $\left(\mu_{u}=2\right)$. Figure 7(b) and (c) represent ductile structures with $\mu_{u}=3$ and 5 , respectively.

The three different structural case models are subjected to 6 different ground motions to examine the $R_{d y n}$

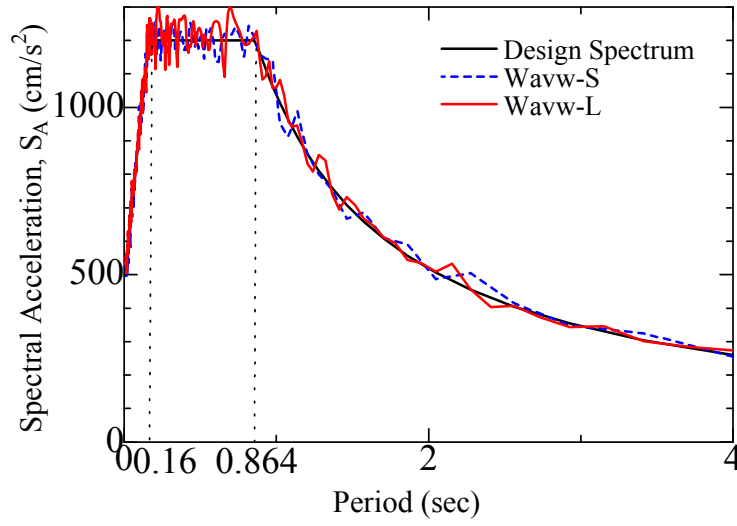

Fig. 8 Acceleration spectrum of simulated ground motions.

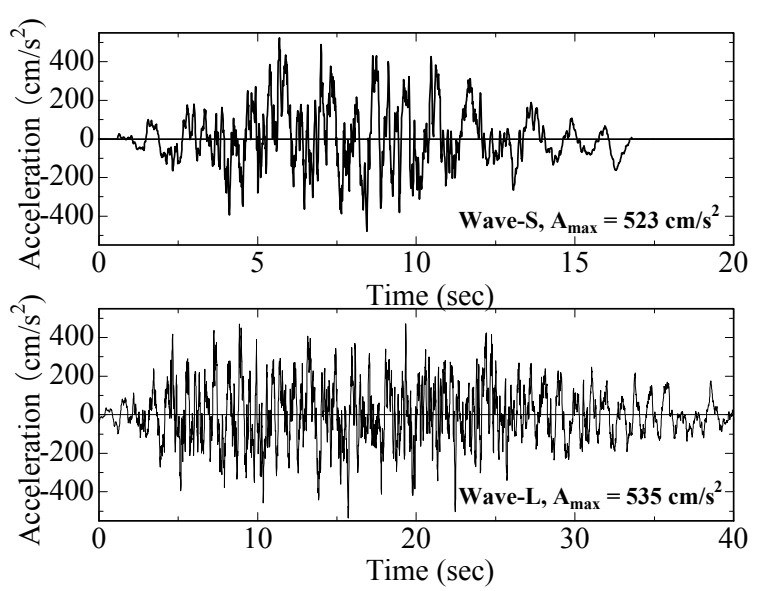

Fig. 9 Time history of simulated ground motions.

index under severe earthquakes. Four of the six ground motions were selected from four different previous earthquakes;

1) The NS component of the $1940 \mathrm{El}$ Centro record (ELC),

2) The NS component of the 1978 Tohoku University record (TOH),

3) The NS component of the 1995 JMA Kobe record (KOB),

4) The N30W component of the 1995 Fukiai record (FKI).

Moreover, two simulated ground motions, Wave-S and Wave-L, were also employed. The acceleration response spectra and time history are shown in Fig. 8 and Fig. 9, respectively. The design acceleration spectrum in the Japanese seismic design code was used as the target spectrum and a Jennings-type envelope curve was assumed to generate the ground motions. The simulated ground motion with a short time duration is named Wave-S while the ground motion with a long time duration is named Wave-L (Fig. 9). Newmark- $\beta$ method with $\beta=1 / 4$ was used to solve the equation of motion. 


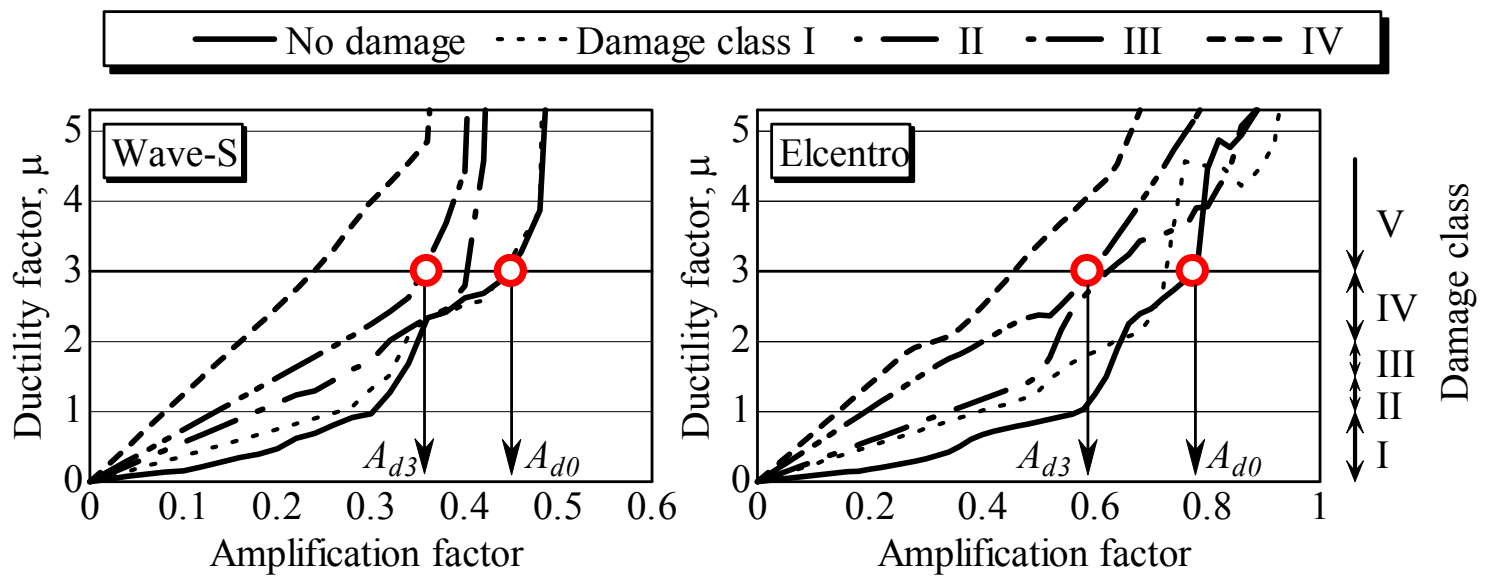

Fig. 10 Amplification factor vs. ductility factor response.

\section{(4) Analytical results}

Parametric studies were carried out utilizing the six ground motions multiplied by amplification factors ranging from 0 to 1 to investigate the relationship between the amplification factor of input ground motion and the maximum ductility factor response. Figure $\mathbf{1 0}$ gives an example of the analytical results for an SDF system with $\mu_{u}=3$ and $\mathrm{T}=0.2 \mathrm{~s}$. using Wave-S and ELC ground motions. The ductility factor $\mu$ increases with increases in the amplification factor. Thick lines indicate the ductility factor $\mu$ of an SDF system without damage. The circles on the thick lines correspond to a point of ultimate ductility factor, $\mu_{u}=3$, and the SDF system is assumed to reach the ultimate limit state. Thus the ultimate amplification factor, which corresponds to the maximum intensity of ground motion, $A_{d 0}$, without damage, can be obtained as shown in Fig. 10. An SDF system was subjected to a set of input ground motions to evaluate the ultimate amplification factor for an SDF system with damage class $i, A_{d i}$; a ground motion (corresponding to main shock) amplified so that the maximum response reached the target ductility factor of the intended damage class was used. Following this, the system was subjected to the ground motion (corresponding to aftershock) with amplification factor ranging from 0 to 1 . Note that $0 \mathrm{~cm} / \mathrm{s}^{2}$ acceleration was input for 5 seconds between the main shock and the aftershock in order to reduce vibration due to the main shock. Figure 11 shows an example of the time history of the ductility factor response. The maximum ductility factor during the main shock remained $\mu=2$ (damage class III) and reached the ultimate ductility factor $\left(\mu_{u}=3\right)$. In this case, we can assume that the SDF system escaped failure during the main shock but collapsed due to the aftershock. The amplification factor for the aftershock employed in Fig. 11 is regarded as the ultimate amplification factor, $A_{d 3}$, for damage class III. The residual seismic capacity ratio, $R_{d y n}$ index, base on seismic response can be evaluated by Eq.(4) described earlier.

The residual capacity ratio, $R_{d v n}$ index, obtained from seismic response analyses with different initial period $T$

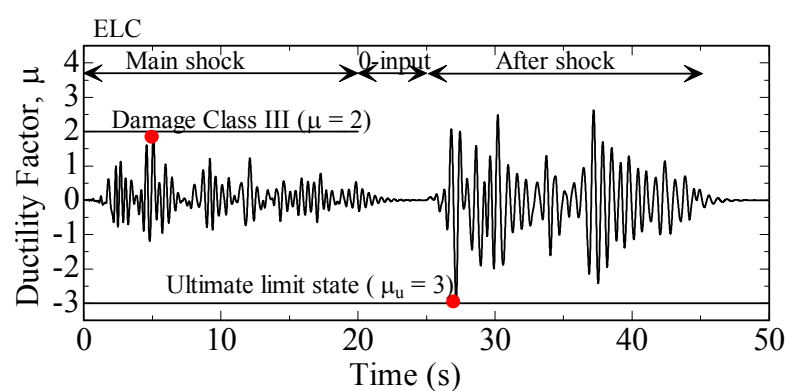

Fig. 11 Response time history for a system subjected to main shock and after shock.

using the six ground motions, is shown in Fig. 12. If a structural system consists of a single structural member, the residual capacity ratio, $R$ index, according to the Damage Evaluation Guideline agrees with the seismic capacity reduction factor $\eta$ (Table 2). The seismic capacity reduction factor $\eta$ is also shown in the figure. As can be seen from the figure, $R_{d y n}$ values based on seismic response analyses range rather widely above the lines, indicating the seismic capacity reduction factor $\eta$, although some of the $R_{d y n}$ plots for damage class I are slightly lower than the $\eta$ values. From the results shown above, $R$ index in the Damage Evaluation Guideline generally gives conservative estimation of $R_{d y n}$ value. It can be concluded that Damage Evaluation Guideline may give conservative, in other words safe, estimation of residual seismic capacity against aftershock for a RC building structure damaged due to earthquakes.

\section{Concluding remarks}

In this paper, the basic concept of the Guideline for Post-Earthquake Damage Evaluation of RC buildings in Japan was presented. The concept and supporting data of the residual seismic capacity ratio, $R$ index, which is assumed to represent post-earthquake damage of a building structure, were discussed. Good agreement between the residual seismic capacity ratio, $R$ index, and 


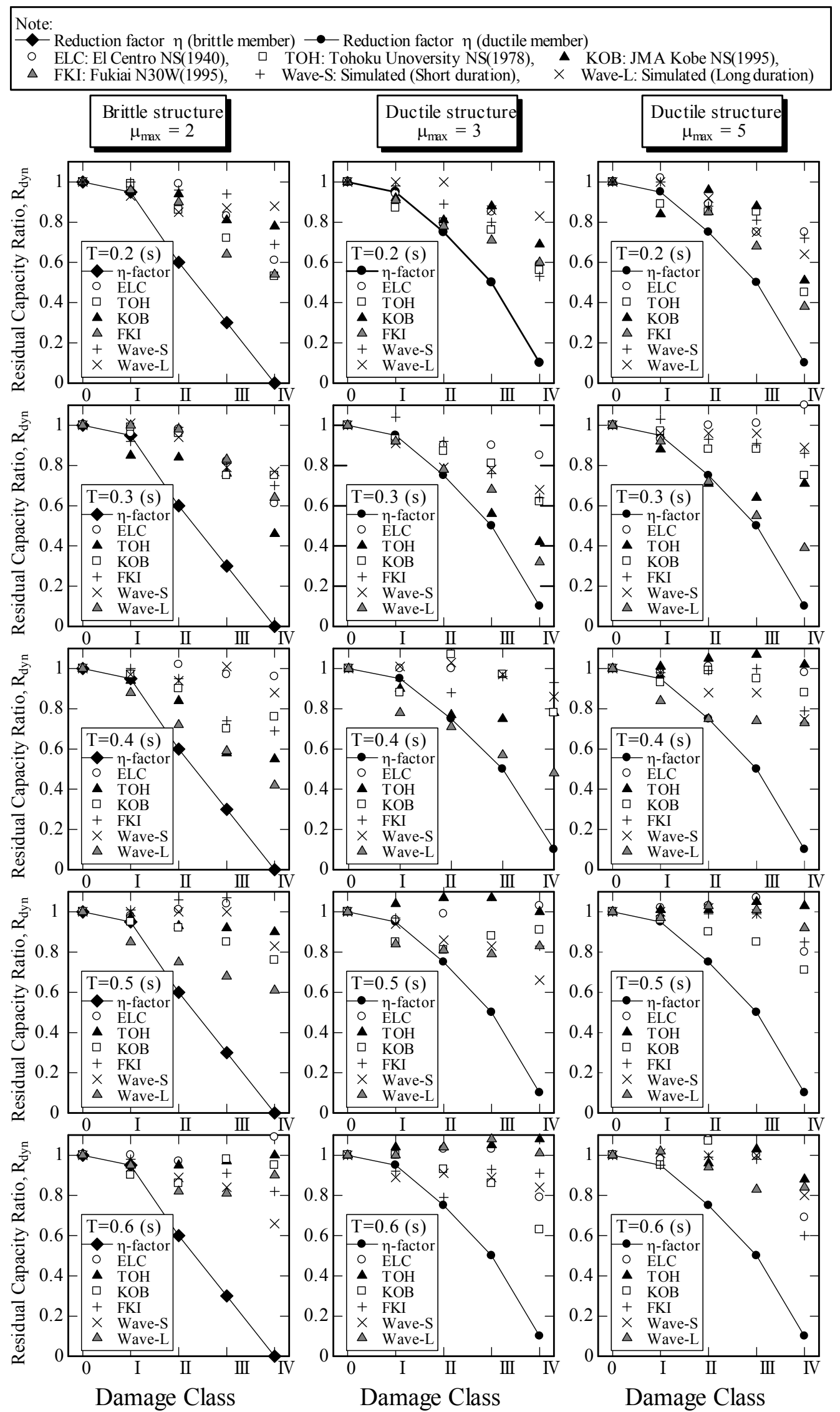

Fig. 12 Comparison of residual capacity ratio $R_{d y n}$ index with values in the Guideline. 
the observed damage levels of RC buildings in recent severe earthquakes was found. Moreover, the validity of the $R$ index was examined through calibration with seismic response analyses of SDF systems. It was observed that the residual seismic capacity of a damaged $\mathrm{RC}$ building structure can be evaluated conservatively according to the $R$ index employed in the Guideline and, practical point of view, $R$ index is an effective to identify the safety of damaged structures against aftershocks.

\section{References}

Bunno, M., Komura, N., Maeda, M. and Kabeyasawa, T. (1999). "Experimental study on behavior of reinforced concrete beams under axial restriction." Proceedings of the Japan Concrete Institute, 21(3), 517-522. (in Japanese)

JBDPA (The Japan Building Disaster Prevention Association). (2001a). Guideline for Post-earthquake Damage Evaluation and Rehabilitation of $R C$ buildings. (in Japanese)

JBDPA (The Japan Building Disaster Prevention Association). (2001b). Standard for Seismic Evaluation of Existing RC Buildings. (in Japanese)

Jung, M., Maeda, M., Tasai, A. and Nagata, M. (2002). "Estimation of residual seismic performance for $\mathrm{R} / \mathrm{C}$ building damage due to earthquake." Journal of Structural Engineering, Architectural Institute of Japan, 48B, 189-196. (in Japanese)

Hyogo Prefectural Government (1998). The Great Hanshin-Awaji Earthquake Assessment Reports of Global Assessment of Earthquake Countermeasures.

Maeda, M. and Bunno, M. (2001). "Post-earthquake damage evaluation for $\mathrm{R} / \mathrm{C}$ buildings based on residual seismic capacity in structural members." The Third US-Japan Workshop on Performance-Based Earthquake Engineering for Reinforced Concrete Building Structures, 157-169.

Maeda, M., Nakano, Y. and Lee, K. S. (2004). "Post-earthquake damage evaluation for $\mathrm{R} / \mathrm{C}$ buildings based on residual seismic capacity." The $13^{\text {th }}$ World Conference on Earthquake Engineering (CD-ROM).

Takeda, T., Mete, A., Sozen, M. and Norby Nielsen, N. (1970), "Reinforced concrete response to simulated earthquakes." Journal of the Structural Division, ASCE, 96(12), 2557-2573.

\section{Appendix \\ -Basic Concept of Japanese Standard for Seismic Evaluation of Existing RC Buildings-}

The Standard consists of three procedures of different levels, i.e., first, second and third level procedures. The first level procedure is the simplest but most conservative since only the sectional areas of columns and walls and concrete strength are considered to calculate the strength, and the inelastic deformability is neglected. In the second and third level procedures, the ultimate lateral load carrying capacity of vertical members or frames is evaluated using material and sectional properties together with reinforcing details based on field inspections and structural drawings.

In the Standard, the seismic performance index of a building is expressed by the $I s$ index for each story and each direction, as shown in Eq. (5)

$$
I s=E_{0} \times S_{D} \times T
$$

where, $E_{0}$ : basic structural seismic capacity index calculated from the product of strength index $(C)$, ductility index $(F)$, and story index $(\phi)$ at each story and each direction when a story or building reaches the ultimate limit state due to lateral force, i.e., $E_{0}=\phi \times C \times F$.

Strength index $C$ : index of story lateral strength, calculated from the ultimate story shear in terms of story shear coefficient.

Ductility index $F$ : index of ductility, calculated from the ultimate deformation capacity normalized by the story drift of $1 / 250$ when a standard size column is assumed to fail in shear. $F$ is dependent on the failure mode of the structural members and their sectional properties such as bar arrangement, shear-span-to-depth ratio, shear-to-flexural-strength ratio, etc. In the standard, $F$ is assumed to vary from 1.27 to 3.2 for ductile columns, 1.0 for brittle columns and 0.8 for extremely brittle short columns (shear-span-to-depth ratio less than 2).

$\phi$ : index of story shear distribution during earthquake, estimated by the inverse of design story shear coefficient distribution normalized by base shear coefficient. A simple formula of $\phi=\frac{n+1}{n+i}$ is basically employed for the $i$-th story level of an $n$-storied building by assuming inverted triangular shaped deformation distribution and uniform mass distribution.

$S_{D}$ : factor to modify $E_{0}$-Index due to stiffness discontinuity along stories, eccentric distribution of stiffness in plan, irregularity and/or complexity of structural configuration, basically ranging from 0.4 to 1.0

$T$ : reduction factor to allow for the deterioration of strength and ductility due to age after construction, fire and/or uneven settlement of foundation, ranging from 0.5 to 1.0 . 